\title{
The Role of Cellular Fibronectin in the Interaction of Human Endothelial Cells with Polymers
}

\author{
A. Dekker, ${ }^{*}$ T. Beugeling, ${ }^{\ddagger}$ A. Poot, J. Spijkers, J. A. van Mourik, J. Feijen, A. \\ Bantjes \& W. G. van Aken
}

University of Twente, P.O. Box 217, 7500 Enschede, The Netherlands

\begin{abstract}
During in-vitro adhesion, spreading and proliferation of human endothelial cells (HEC) on tissue culture polystyrene (TCPS), cellular fibronectin is deposited onto the surface of TCPS in spite of the fact that relatively large amounts of proteins have been adsorbed from the serum-containing culture medium to this surface. Evidence is presented that serium proteins, adsorbed to the TCPS surface, are displaced by cellular fibronectin. In addition, the interaction of HEC with polyethylene, precoated with monoclonal antibodies directed against HEC membrane antigens and against extracellular matrix compounds, was studied. $\mathrm{F}\left(\mathrm{ab}^{\prime}\right)_{2}$ fragments of two monoclonal antibodies were also included in this study. Preadsorption of these antibodies and $F\left(a^{\prime}\right)_{2}$ fragments resulted in cell adhesion and spreading as well as moderate cell proliferation (or no proliferation) for several days. A good cell proliferation of HEC was only observed on polyethylene precoated with fibronectin or an antibody directed against fibronectin. The results indicate that the direct or indirect deposition of fibronectin is a prerequisite for the proliferation of HEC. It is suggested that fibronectin, bound to a solid substrate, provides a biochemical signal necessary for the proliferation of HEC.
\end{abstract}

\section{INTRODUCTION}

A systematic study on the interaction of human endothelial cells (HEC) with polymers may lead to the development of vascular grafts, which allow the formation of an endothelial lining on the luminal surface.

HEC, suspended in culture medium containing $20 \%$ human serum, adhere and spread well on moderately wettable polymers like tissue culture polystyrene (TCPS). ${ }^{1}$ During adhesion and spreading, cellular fibronectin is deposited onto the TCPS surface in spite of the fact that proteins such as albumin, high-density lipoprotein and immunoglobulin $G$ have been adsorbed from the serumcontaining culture medium to this surface..$^{2-4}$ These results suggest that the desorption of cellular fibro-

\footnotetext{
${ }^{*}$ To whom correspondence should be addressed.

"Present address." Institute of Pathology, Technical University of Aachen, Klinikum der RWTH, Pauwelsstraße, D-5100 Aachen, Germany.
}

nectin is accompanied by desorption of adsorbed serum proteins. In order to test this hypothesis, the decrease of the amount of albumin, previously adsorbed to TCPS from (solutions) of serumcontaining culture medium, was measured after incubation of the pretreated TCPS with a suspension of HEC. The amount of fibronectin, deposited by HEC on the pretreated ICPS, was also determined. The displacement of surface-adsorbed proteins by cellular fibronectin will occur more easily in the case of relatively hydrophilic surfaces compared to hydrophobic surfaces, because proteins are more strongly adsorbed to the latter surfaces. ${ }^{5,6}$ Most probably as a result of this phenomenon, HEC do not adhere, spread and proliferate on hydrophobic polymers like polyethylene and polytetrafluoroethylene (Teflon), ${ }^{7,8}$ However, hydrophobic polymers to which fibronectin has been preadsorbed, give rise to adhesion, spreading and proliferation of HEC. ${ }^{4}$

It has been reported that adhesion and spreading 
of baby-hamster kidney (BHK) cells can be achieved by a substratum-adsorbed antibody, which is directed against BHK cell membranes. ${ }^{9}$ We investigated the interaction of HEC with polyethylene, precoated with monclonal antibodies directed against cell membrane glycoproteins and against extracellular matrix compounds of HEC. In addition, $F\left(a b^{\prime}\right)_{2}$ fragments of a monoclonal antibody directed against an endothelial cell membrane glycoprotein, and $\mathrm{F}\left(\mathrm{ab}^{\prime}\right)_{2}$ fragments of a monoclonal antibody directed against cellular fibronectin, were included in this study. The results with respect to adhesion, spreading and proliferation of HEC on these surfaces were compared with the results of experiments in which polyethylene had been precoated with purified human plasma fibronectin.

\section{MATERIALS AND METHODS}

\section{Coating of TCPS with (diluted) serum-containing culture medium}

Twenty-four-well clusters of TCPS (Costar Europe) were used for EIA determinations of adsorbed protcins (sce below). Forty-eight-well clusters of TCPS were used for experiments in which radio-iodinated human scrum albumin was present as tracer protein. For these experiments, ${ }^{131}$ I-labeled human serum albumin (Medgcnix, Fleurus, Belgium) was added to human serum-containing culture medium to a final concentration of $0.012 \mathrm{mg} / \mathrm{ml}$.

The wells of the clusters were exposed to serumcontaining culturc medium or solutions of serumcontaining culture medium in phosphate-buffered saline (PBS) for $1 \mathrm{~h}$ at room tempcrature. After incubation with (solutions of) serum-containing culture medium, the wells were rinsed three times with PBS.

\section{Determination of the amounts of adsorbed human serum albumin and (cellular) fibronectin}

The relative amounts of adsorbed albumin were determined either by means of a two-step enzymeimmunoassay $(\mathrm{EI} \Lambda)^{2,10}$ or by counting the amount of adsorbed ${ }^{131}$ I-labeled human serum albumin. ${ }^{11}$ The adsorbed amounts of fibronectin were determined with the EIA. ${ }^{2,10}$ In order to make the adsorbed proteins beneath the layer of adherent HEC accessible to the first antibody solution of the EIA, the cells were lysed with $0.1 \mathrm{~N}$ ammonia for $10 \mathrm{~min},{ }^{2}$ followed by rinsing three times with PBS.
Toble 1. Monocional antibodies

\begin{tabular}{ll}
\hline Code & Directed Against \\
\hline CLB-HEC-19 & Membrane glycoprotein of HEC \\
CLB-HEC-347 & Membrane glycoprotein of HEC \\
CLB-10G11 & Glycoprotein Ia-Ila \\
CLB-HEC-65 & Glycoprotein IIa* (CD31) \\
CLB-C17 & Glycoprotein Ilb-IIIa \\
CLB-Rag 38 & Fon Willebrand factor \\
CLB-HEC-FN-140 & Human fibronectin \\
Anti-erythrocyte & Erythrocytes; glycophorin A
\end{tabular}

\section{Fibronectin purification}

The purification of human plasma fibronectin has been described in Ref. 7

\section{Monoclonal antibodies and $\mathbf{F}\left(\mathbf{a b}^{\prime}\right)_{2}$ fragments}

All monoclonal antibodies (see Table 1) were prepared and characterized in the Central Laboratory of the Netherlands Red Cross Blood Tranfusion Service (CLB), Amsterdam, The Netherlands. The purification of antibodies has been described in Ref. 7.

$F\left(a b^{\prime}\right)_{2}$ and $F c$ fragments were prepared by means of digestion of purified antibodies with Sepharose-immobilized pepsin (Pierce Rockford, II). $F\left(a b^{\prime}\right)_{2}$ and $F c$ fragments were separated by chromatography on protein-A-Sepharose.

Coating of polyethylene with fibronectin, antibodies and $\mathbf{F}\left(\mathbf{a b}^{\prime}\right)_{2}$ fragments

Sheets of low-density polyethylene (Talas, Ommen, The Netherlands) were cleaned as described in Ref. 10 and mounted in test devices similar to those shown in Ref. 1 and 10. Thereafter, the sheets were exposed to protein solutions of $0.05 \mathrm{mg} / \mathrm{ml}$ at $4^{\circ} \mathrm{C}$ for $15-17 \mathrm{~h}$.

\section{Cell adhesion and proliferation}

HEC were isolated from human umbilical cord veins according to the method of Willems et al. ${ }^{12}$ Cells were routinely cultured in TCPS flasks (Costar Europe, Badhoevedorp, The Netherlands) precoated with partially purified fibronectin. ${ }^{1}$ Cells were harvested by means of trypsin $(0.015 \%)$, after which trypsin was inactivated by addition of serumcontaining culture medium. Subsequently, the iso- 


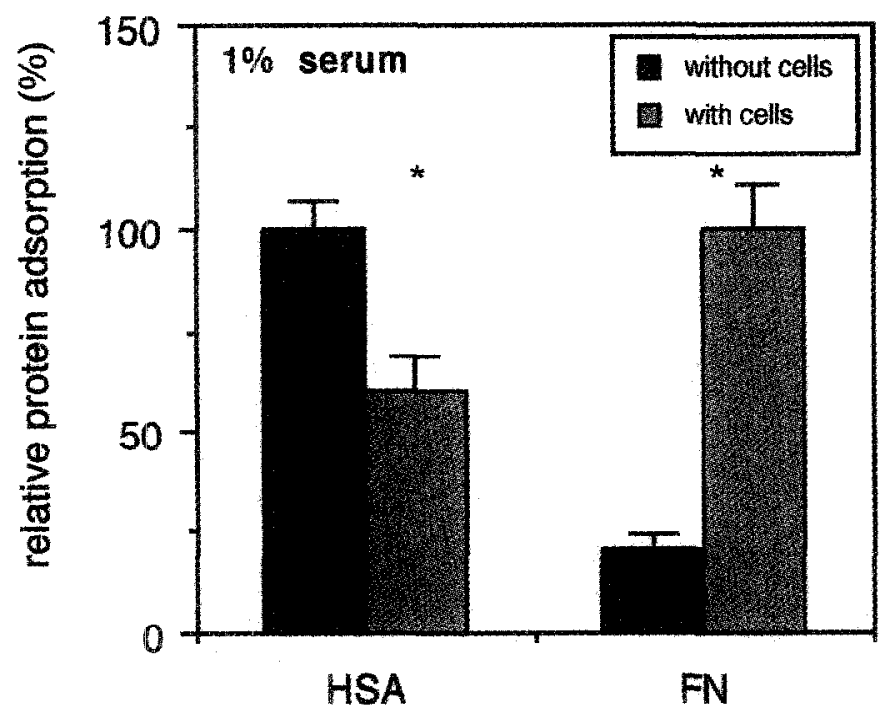

(a)

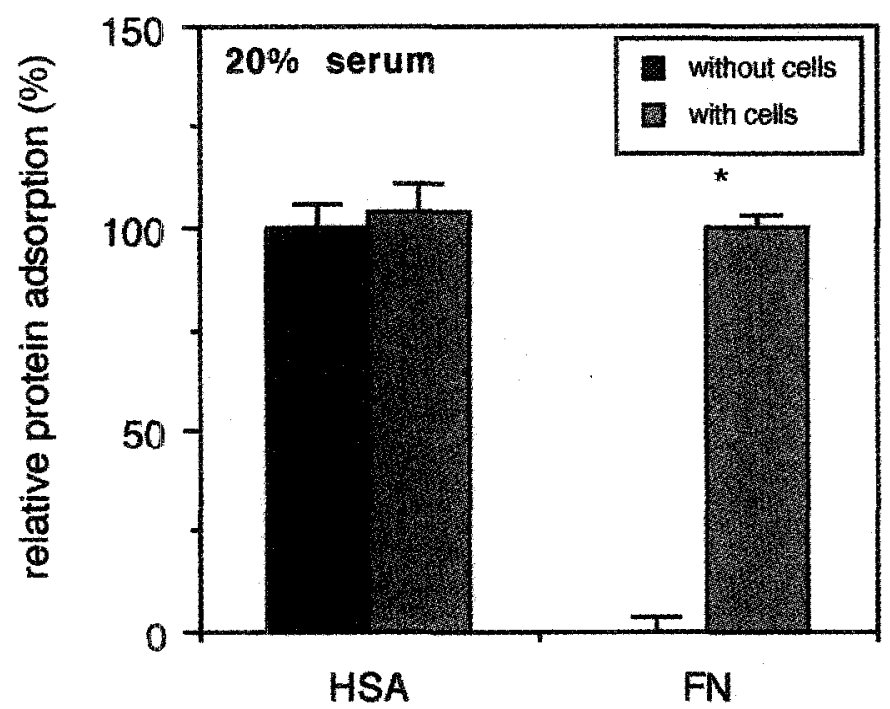

(b)

Fig. 1. Relative amounts of adsorbed human serum albumin (HSA) and fibronectin (FN) on TCPS which had been exposed for $1 \mathrm{~h}$ to (a solution of) serum-containing culture medium ((a): $1 \%$ serum; (b): $20 \%$ serum), followed by incubation for $6 \mathrm{~h}$ with serum-free medium either with endothelial cells $\left(200000\right.$ per $\mathrm{cm}^{2}$ ) or without cells.

Detection: enzyme-immunoassay. In each experiment the amount of HSA adsorbed to TCPS after incubation with serum-free medium lacking cells was taken as $100 \%$, and the adsorbed amount of FN after incubation with a cell suspension in serum-free medium was taken as $100 \%$. Values are means of four determinations $( \pm \mathrm{SD})$. Unpaired $t$ test: ${ }^{*} P>0.0005$ compared to the amount of adsorbed protein after incubation with medium lacking cells.

lated cells were washed three times with culture medium lacking serum and resuspended in serumfree medium. HEC were seeded into the wells of the test devices mentioned above. The cell suspensions used for seeding contained 125000 cells/ $\mathrm{cm}^{2}$ and 31000 cells $/ \mathrm{cm}^{2}$ for adhesion and pro- liferation experiments, respectively. Adhesion and proliferation experiments were carried out at $37^{\circ} \mathrm{C}$. Cell adhesion was measured after $2 \mathrm{~h}$ and cell proliferation was determined after 2,6 and 9 days. In the proliferation experiments the cells were allowed to adhere for $2 \mathrm{~h}$, after which the serumfree medium was replaced by serum-containing medium.

The number of adherent cells was determined eithcr by counting the nuclci of the cells with a flow cytometer (Technicon, Avelingen, The Netherlands) or by measuring the amount of DNA by means of Hoeschst dye 33258 . $^{13,14}$

In the cxpcriments in which the adsorbed amounts of human serum albumin and fibronectin were determined, HEC (200000 cells $/ \mathrm{cm}^{2}$ in serum-free medium) were allowed to adhere to TCPS for $6 \mathrm{~h}$. Control experiments were carried out in the same way, using serum-free medium lacking cells.

\section{RESULTS AND DISCUSSION}

In order to investigate whether or not a displacement of adsorbed serum proteins by cellular fibronectin would occur, a IIEC suspension in serumfree culture medium was pipetted into TCPS wells which had been pre-exposed to serum-containing culture medium or to solutions of this medium. In simultaneous experiments, pre-exposed TCPS wells were incubated with serum-free medium lacking cells. The relative amount of adsorbed fibronectin and human serum albumin (HSA) present on the TCPS surfaces after incubation with a HEC suspension as well as after incubation with serum-free medium were determined with an enzyme-immunoassay (EIA). ${ }^{2}$ The results of the EIA determinations are shown in the graphs of Fig. 1(a) and (b). These graphs reveal that, irrespective of the serum concentration in the coating solution, the amount of fibronectin on the TCPS surface is much higher if the surface had been incubated with HEC suspension in culture medium instead of culture medium lacking cells. This is in agreement with the results obtained by Van Wachem $e t$ $a l^{2}$ The experiments prove that adhering and spreading HEC deposit cellular fibronectin onto the TCPS surface.

It was found that the amount of HSA adsorbed to TCPS which had been pre-exposed to a solution of culture medium containing $1 \%$ serum (or less), followed by incubation with a HEC suspension in serum-free medium, was decreased compared to 


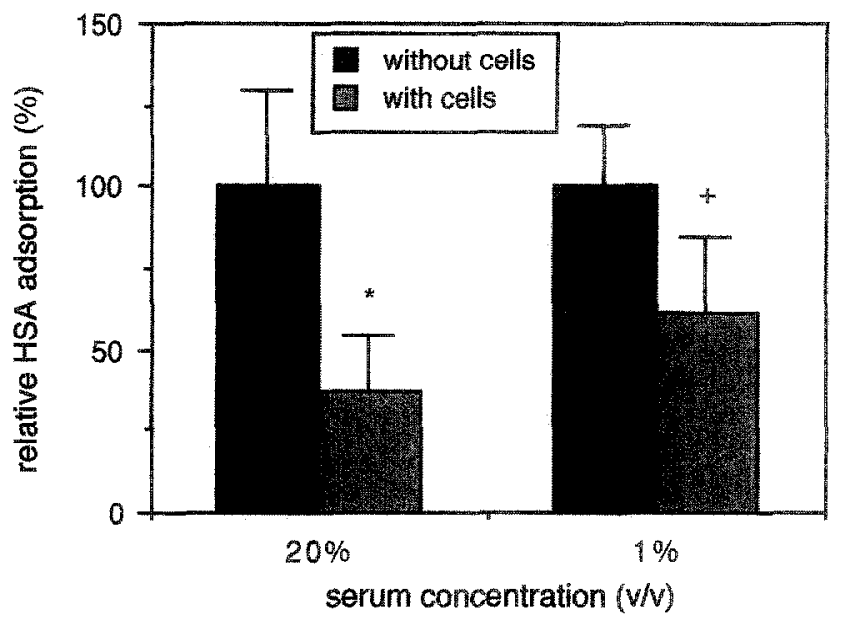

Fig. 2. Relative amounts of adsorbed human serum albumin (HSA) on TCPS, which had been exposed for $1 \mathrm{~h}$ to (a solution of) serum-containing culture medium $(20 \%$ and $1 \%$ serum, respectively, supplemented with ${ }^{131}$ I-labeled HSA), followed by incubation for $6 \mathrm{~h}$ with serum-free medium either with endothelial cells $\left(200000\right.$ per $\left.\mathrm{cm}^{2}\right)$ or without cells.

Detection: $\gamma$-ray counting of TCPS wells. In each experiment, the amount of HSA adsorbed to TCPS after incubation with serum-free medium lacking cells was taken as $100 \%$. Values are means of four determinations ( $\pm \mathrm{SD}$ ). Unpaired $t$ test: ${ }^{*} P<0.01 ;{ }^{+} P<0.025$ compared to the amount of adsorbed HSA after incubation with medium lacking cells.

the pretreated TCPS which had been incubated with serum-free medium lacking cells (Fig. 1(a)). However, if $20 \%$ serum was present in the precoating solution, no decrease of the amount of adsorbed HSA due to the presence of cells could be observed (Fig. 1(b)). Most probably, the EIA is not suitable to detect differences between different amounts of adsorbed HS $\Lambda$, when these amounts are large. ${ }^{2}$

A decrease in the amount of adsorbed HSA after adhesion and spreading of HEC on TCPS, which had been pre-exposed to (solutions of) serum-containing culture medium, was also determined with the aid of experiments in which ${ }^{131}$ I-labeled HSA was added as tracer protein to the serum solutions. The concentrations of human serum in the solutions used for the pre-exposure of TCPS were taken as $1 \%$ and $20 \%$. Figure 2 shows the results of experiments in which the relative amounts of adsorbed HSA were determined by measuring the amounts of ${ }^{131}$ I-labeled HSA on the TCPS surfaces. From this figure, it may be concluded that a decrease in the amount of adsorbed HSA also occurred if TCPS had been pretreated with a solution containing $20 \%$ human serum.

The most plausible explanation for the results mentioned above is that previously adsorbed serum proteins were displaced by cellular fibronectin during adhesion and spreading of HEC on TCPS. It has been mentioned in the introduction

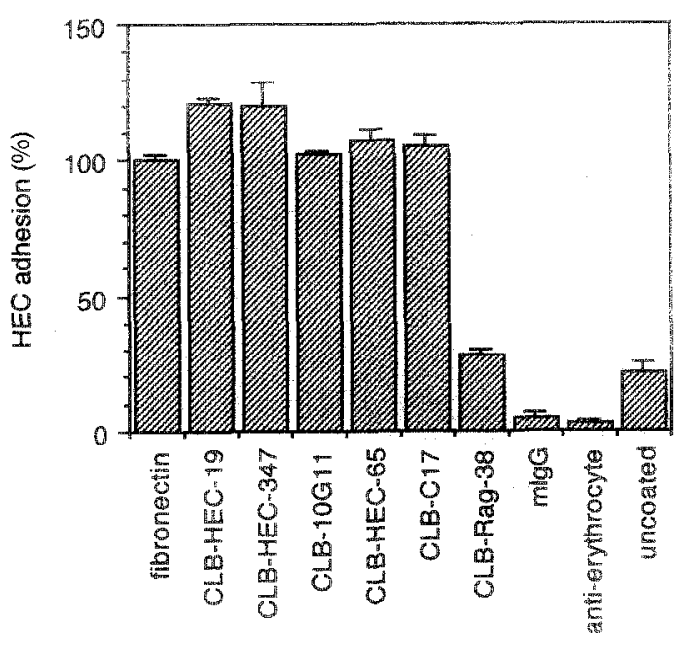

Fig. 3. Adhesion of endothelial cells onto uncoated polyethy. elene and polyethylene coated with various antibodies after $2 \mathrm{~h}$ of incubation. Cell adhesion is expressed as the percentage of the number of cells adhered to polyethylene coated with fibronectin. All values are means of four determinations ( $\pm S D$ ).

that the displacement of adsorbed serum proteins by cellular fibronectin will occur more easily in the case of relatively hydrophilic surfaces (like TCPS) compared to hydrophobic surfaces. As a result, HEC do not adhere, spread and proliferate on hydrophobic polymers, unless these polymers have been precoated with fibronectin. ${ }^{4}$

Another method of binding cells to a solid surface was reported by Grinnell and Hays ${ }^{9}$ and involves the use of substratum-bound antibodies, which are directed against plasma membrane proteins of the cells. We investigated the adhesion, spreading and proliferation of HEC on polyethylene, precoated with monoclonal antibodies directed against cell membrane glycoproteins and against extracellular matrix compounds. In addition $F\left(a b^{\prime}\right)_{2}$ fragments of two of these monoclonal antibodies were included in this study,

Figure 3 shows the results with respect to the adhesion of HEC to uncoated polyethylene and polyethylene precoated with the various anti-HEC antibodies. The results of HEC adhesion to polyethylene precoated with fibronectin, mouse $\operatorname{IgG}$ and anti-erythrocyte are also shown in this figure. The largest numbers of adherent HEC were observed on surfaces coated with the monoclonal antibodies CLB-HEC-19 and CLB-HEC-347. The adhesion of HEC on polyethylene precoated with the antibodies CLB-10G11, CLB-HEC-65 and CLB-C17 was similar to the adhesion on the fibronectin-coated surface. Cell spreading on the polyethylene surfaces coated with CLB-HEC-19, CLBHEC-347, CLB-10G11, CLB-HEC-65 and CLB$\mathrm{C} 17$ was not quite as good as on the reference surface. 


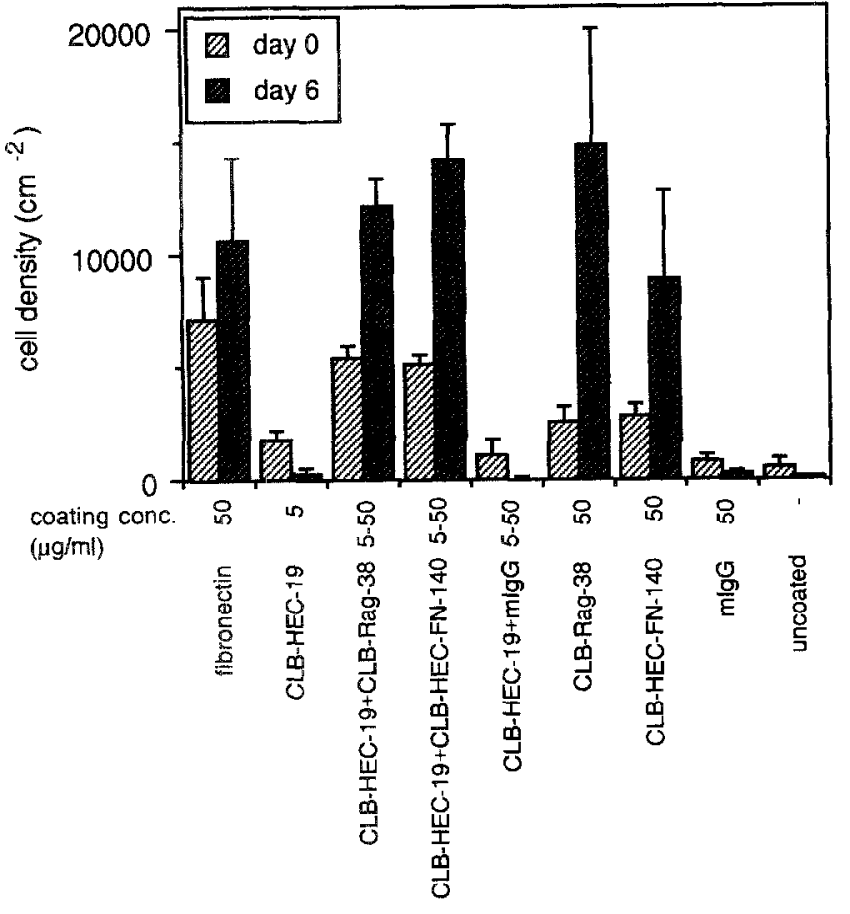

Fig. 4. Proliferation of endothelial cells after $2 \mathrm{~h}(-0$ days) and 6 days on uncoated polyethylene, on fibronectin-coated polyethylene, on polyethylene coated with antibodies and on polyethylene coated with mixtures of antibodies. Values are means of three determinations $( \pm \mathrm{SD})$.

Significantly less cell adhesion was observed on polyethylene coated with CLB-Rag-38 (directed against von Willebrand factor) and on uncoated polyethylene. IIEC were not well spread on these surfaces. As expected, HEC hardly adhered to polyethylene coated with mouse IgG or antierythrocyte.

Polyethlene precoated with CLB-IIEC-FN-140 (directed against fibronectin) was not included in the experiments from which the results are presented in Fig. 3, but the results of HEC adhesion $(0$ days $-2 \mathrm{~h})$ and proliferation ( 6 days) on this surface are shown in Fig. 4, together with the results of IIEC adhesion and proliferation on polyethylene precoated with the antibodies CLB-HEC-19, CLB-Rag-38 and mouse IgG. HEC adhesion and proliferation on uncoated polyethylene and polyethylene coated with fibronectin were also determined.

The numbers of HEC that adhered after $2 \mathrm{~h}$ to polyethylene coated with CLB-Rag-38 (Figs 3 and 4), and CLB-HEC-FN-140 (Fig. 4) were rather low compared with the number of cells that adhered to the fibronectin-coated surface. HEC showed a very good adhesion to the CLB-HEC-19 surface (Fig. 3) but HEC did not proliferate on this surface. Therefore, HEC adhesion and proliferation were also determined on polyethylene precoated with mixtures of antibodies. The results of these experiments are also presented in Fig. 4. HEC did not proliferate on polyethylene coated with mixtures of antibodies in which relatively high concentrations of CLB-HEC-19 were present. ${ }^{7}$ For this reason, the concentration of CLB-HEC-19 in the coating solutions was kept rather low $(5 \mu \mathrm{g} / \mathrm{ml})$.

Proliferation of HEC determined after 6 days was found to occur on polyethylene coated with fibronectin, CLB-HEC-FN-140, CLB-Rag-38, mixtures of CLB-HEC-19 and CLB-Rag-38, and mixtures of CLB-HEC-19 and CLB-HEC-FN-140 (Fig. 4).

It must be mentioned, however, that cell spreading on polycthylenc precoated with CLB-Rag-38 (directed against von Willebrand factor) or the mixture of antibodics in which CLB-Rag-38 was present, was not very good. In these cases, the edges of many cells had been detached from the material surface. In agreement with earlier results from our laboratory, ${ }^{4,7}$ HEC did not proliferate on uncoated polyethylene and polyethylene coated with mouse IgG. HEC also did not proliferate on polyethylene treated with a solution containing a low concentration of CLB-HEC-19 $(5 \mu \mathrm{g} / \mathrm{ml})$.

Earlier experiments ${ }^{11}$ showed that proliferation of HEC did not occur or hardly occurred on polyethylene precoated with the antibodies CLB-HEC$19(50 \mu \mathrm{g} / \mathrm{ml})$, CLB-HEC-347, CLB-10G11, CLBHEC-65 and CLB-C17. These antibody-coated surfaces gave rise to good cell adhesion (Fig. 3). Evidently, attachment and spreading of HEC on a solid surface docs not automatically lead to cell proliferation.

Intact monoclonal antibodics, adsorbed to a solid surface, may interact with blood platelets via their Fc part. ${ }^{15}$ By prccoating of vascular grafts with $\mathrm{F}\left(\mathrm{ab}^{\prime}\right)_{2}$ fragments of monoclonal antibodies instead of intact antibodies, platelet adhesion may thus be prevented. For this reason, polyethylene coated with $\mathrm{F}\left(\mathrm{ab}^{\prime}\right)_{2}$ fragments was also included in the proliferation studies.

In Fig. 5 the results are shown with respect to the proliferation of HEC, determined after 2, 6 and 9 days, on polyethylene precoated with fibronectin and on polyethylene precoated with mixtures consisting of intact antibodies, mixtures of antibodies and $\mathrm{F}\left(\mathrm{ab}^{\prime}\right)_{2}$ fragments, and a mixture of $\mathrm{F}\left(\mathrm{ab}^{\prime}\right)_{2}$ fragments.

HEC proliferated well on polyethylene coated with a mixture of intact CLB-HEC-FN-140 and $\mathrm{F}\left(\mathrm{ab}^{\prime}\right)_{2}$ fragments of CLB-HEC-19. HEC showed a moderate-to-good proliferation on polyethylene coated with a mixture of the intact monoclonal anti- 


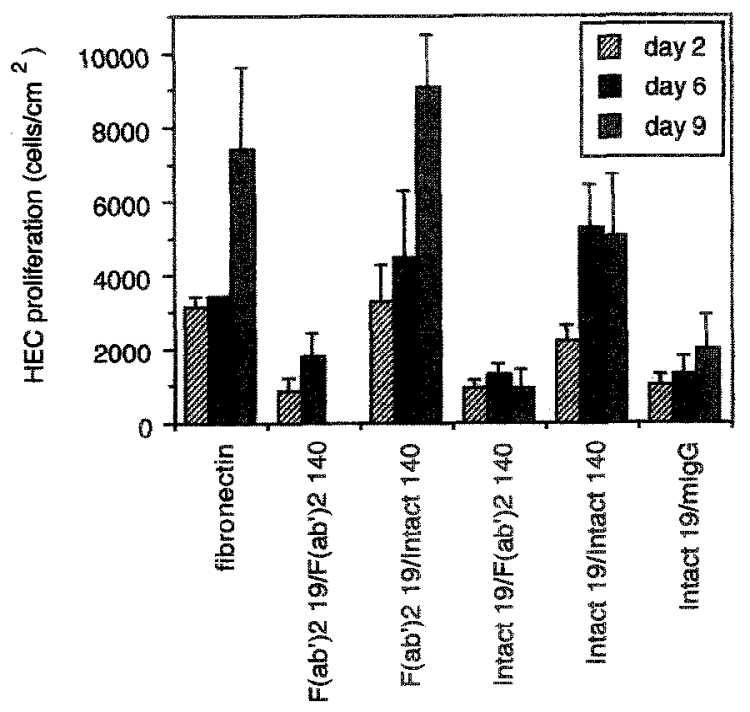

Fig. 5. Proliferation of endothelial cells after 2,6 and 9 days on fibronectin-coated polyethylene, on polyethylene coated with mixtures of antibodies, on polyethylene coated with mixtures of antibodies and $F\left(a b^{\prime}\right)_{2}$ fragments, and on polyethylene coated with a mixture of $\mathbf{F}\left(\mathrm{ab}^{\prime}\right)_{2}$ fragments. Values are means of three determinations $( \pm S D)$.

bodies CLB-HEC-19 and CLB-HEC-FN-140. This result is in agrecment with the results presented in Fig. 4. A good cell spreading was observed in experiments in which HEC proliferated well.

The results obtained from our proliferation experiments carried out thus far suggest that a good proliferation of HEC only takes place on polyethylene which has been prccoated with fibronectin or on polyethylene which can indirectly bind (cellular) fibronectin via CLB-HEC-FN-140.

Figure 5 shows that $\mathrm{HEC}$ hardly proliferated when $F\left(a b^{\prime}\right)_{2}$ fragments of CLN-HEC-FN-140 instead of intact antibody molecules were adsorbed to polyethylene. This may be explained by a reduced capacity of the adsorbed $F\left(a b^{\prime}\right)_{2}$ fragments to bind fibronectin ( $\pm 40 \%$ compared to the capacity of the intact antibody) and is probably caused by the preparation procedure for obtaining $\left(\mathrm{Fab}^{\prime}\right)_{2}$ fragments. It is also possible that the adsorption of the $F\left(a b^{\prime}\right)_{2}$ fragments onto polyethylene occurs in such a way that the $F\left(a b^{\prime}\right)_{2}$ fragments cannot properly bind (cellular) fibroncctin. Ifardly any proliferation of HEC was observed on polyethylene precoated with a mixture of the antibodies CLB-HEC-19 and mouse IgG. This is in agreement with the results mentioned before.

A dependence of HEC proliferation upon fibronectin, directly or indirectly bound to a substratum, explains why HEC do not proliferate on polyethylene precoated with antibodies or $F\left(\mathrm{ab}^{\prime}\right)_{2}$ fragments which do not bind fibronectin. The hydro- phobic polyethylene strongly adsorbs proteins; therefore, these antibodies or $\mathrm{F}\left(\mathrm{a} \mathrm{b}^{\prime}\right)_{2}$ fragments are not easily displaced from the polyethylene surface by cellular fibronectin.

If substratum-bound fibronectin is really a prerequisite for the proliferation of $\mathrm{HEC}$, it is conccivable that part of the bound fibronectin molecule provides a biochemical signal which initiates a series of events in the endothelial cell, leading to DNA replication. Probably HEC are also triggered by this biochemical signal to synthesize and secrete cellular fibronectin. More cxperiments have to be carried out, however, in order to come to conclusions about such a rolc of fibroncctin.

\section{ACKNOWLEDGEMENT}

Financial support by the Netherlands Heart Foundation (Grant no 88.078) is gratefully acknowledged.

\section{REFERENCES}

1. Van Wachem, P. B., Beugeling, T., Feijen, R., Bantjes, J., Detmers, J. P. \& Van Aken, W. G., Interaction of cultured human endothelial cells with polymeric surfaces of different wettabilities. Biomaterials, 6 (1985) 403-8.

2. Van Wachem, P. B., Mallens, B. W. L., Dekker, A., Beugeling, T., Feijen, J., Bantjes, A., Detmers, J. P. \& Van Aken, W. G., Adsorption of fibronectin derived from serum and from human endothelial cells onto tissue culture polystyrene. J. Biomed. Mater. Res., 21 (1987) 1317-27.

3. Van Wachem, P. B., Beugeling, T., Mallens, B. W. L., Dekker̈, A., Feijen, J., Bantjes, A. \& Van Aken, W. G., Deposition of endothelical fibronectin on polymeric surfaces. Biomaterials, 9 (1988) 121-3.

4. Van Wachem, P. B., Vreriks, C. M., Beugeling, T., Feijen, J., Bantjes, A., Detmers, J. P. \& Van Aken, W. G., The influence of protein adsorption on interactions of cultured human endothelial cells with polymers. $J$. Biomed. Mater. Res., 21 (1987) 710-18.

5. Feijen, J., Beugeling, T., Bantjes, A., \& Smit Sibinga, C. Th., Biomaterials and interfacial phenomena. In Advances in Cardiovascular Physics, Vol. 3, ed. D. N. Ghista, Karger-Basel, 1979, pp. 100-32.

6. Brash, J. L., Mechanism of adsorption of proteins to solid surfaces and its relationship to blood compatibility. In Biocompatible Polymers, Metals and Composites, ed. M. Szycher. Technomic, Lancaster, USA, 1983, p. 35.

7. Dekker, A., Poot, A. A., Van Mourik, J. A., Workel, M. P. A., Beugcling, T., Bantjes, A., Feijen, J. \& Yan Aken, W. G., Improved adhesion and proliferation of human endothelial cells on polyethylene precoated with monoclonal antibodies directed against cell membrane antigens and extracellular matrix proteins. Thromb. Haemost., 66 (1991) 715-24.

8. Dekker, A., Reitsma, K., Beugeling, T., Bantjes, A., Feljen, J. \& Van Aken, W. G., Adhesion of endothelial cells and adsorption of serum proteins on gas plastna-treated polym tetrafluoroethylene. Biomaterials, 2 (1991) 130-8. 
9. Grinnell, F. \& Hays, D. G., Induction of cell spreading by substratum-adsorbed ligands directed against the cell surface. Exp. Cell. Res., 116 (1978) 275-84.

10. Poot, A., Beugeling, T., Van Aken, W. G. \& Bantjes, A., Detection of surface-adsorbed (lipo)proteins by mcans of a two-step enzyme-immunoassay: A study on the Vroman effect. J. Biomed. Mater. Res., 24 (1990) 1021-36.

11. Dekker, A., Adhesion and proliferation of human endothelial cells on polymeric surfaces. Optimization studies. $\mathrm{PhD}$ Thesis, University of Twente, Enschede, The Netherlands, 1990.

12. Willems, C., Astaldi, G. C. B., De Groot, P. D., Jansen, M. C., Gonsalves, M. D., Zeijlemaker, W. P., Van Mourik, J. A. \& Van Aken, W. G., Media conditioned by cultured vascular endothelial cells inhibit the growth of vascular smooth muscle cells. Exp. Cell Res., 139 (1982) 191
13. West, D. C., Sattar, A. \& Kumar, S., A simplified in-situ solubilization procedure for the determination of DNA and cell number in tissue cultured mammalian cells. Anal. Biochem., 147 (1985) 289.

14. Matcs, G., Danicl, M. \& Walker, C., Factors affecting the reproducibility of a spectrofluorometric assay for the enumeration of human venous endothelium in culture. Cell Biol. Int. Rep., 10(8) (1986) 641.

15. Poot, A., Dekker, A., Van Mourik, J. A., Spijkers, J., Machielsen, A., Beugeling, T., Bantjes, A., Feijen, J. \& Van Aken, W. G., Promotion of endothelial coverage and decrease of platelet reactivity of artificial surfaces using monoclonal antibodies directed against endothelial cells. In Proceedings of IVth International Symposium on Biology of Vascular Cells. Paris, 28-31 August 1990, p. 60. 